\title{
USE OF VISUAL INFUSION PHLEBITIS (VIP) SCORE TO CARE AND CONTROL INTRAVENOUS (IV) INFUSION RELATED PHLEBITIS
}

\author{
Manashi Sengupta *.
}

SankarMadhab College of Nursing, Assam down town University, Guwahati, Assam, India.

\section{ABSTRACT}

\begin{abstract}
Phlebitis is the inflammation of vein which is a common complication associated with the use of peripheral intravenous (IV) catheters affecting between $27 \%$ and $70 \%$ of all patients receiving IV therapy and association with up to $10 \%$ of S.Aureus bacteremia. Importance factors found to determine phlebitis incidence include the kind of infusion and dwell time of intravenous cannula. The use of the visual infusion phlebitis (VIP) score tool for the assessment of the early signs of phlebitis along with prompt removal of peripheral intravenous cannula has been very successful in reducing below the acceptable rate of $5 \%$. However, achieving this goal depends on strict compliance with guidelines for cannula insertion, documentation and assessment using the VIP tool.

This study aimed to increase the use of VIP scoring tool in the intensive care units and wards during a 6 months period in order to maximize its utility in phlebitis prevention. Nursing audit was carried out, during which assessment and plan of actions were introduced. The first step aimed to make the nurses aware of VIP scoring tool by the use of posters and training sessions. Second the assessment of nurses' knowledge and skill related to the intravenous cannula insertion and use of VIP score tool for the early detection and prompt action related to the care and control of infusion related phlebitis and its documentation.
\end{abstract}

KEY WORDS: VIP score, Phlebitis.

Address for correspondence: Prof (Mrs) Manashi Sengupta, SankarMadhab College of Nursing, Assam down town University, Guwahati, Assam, India. E-Mail: manashi_sengupta@rediffmail.com

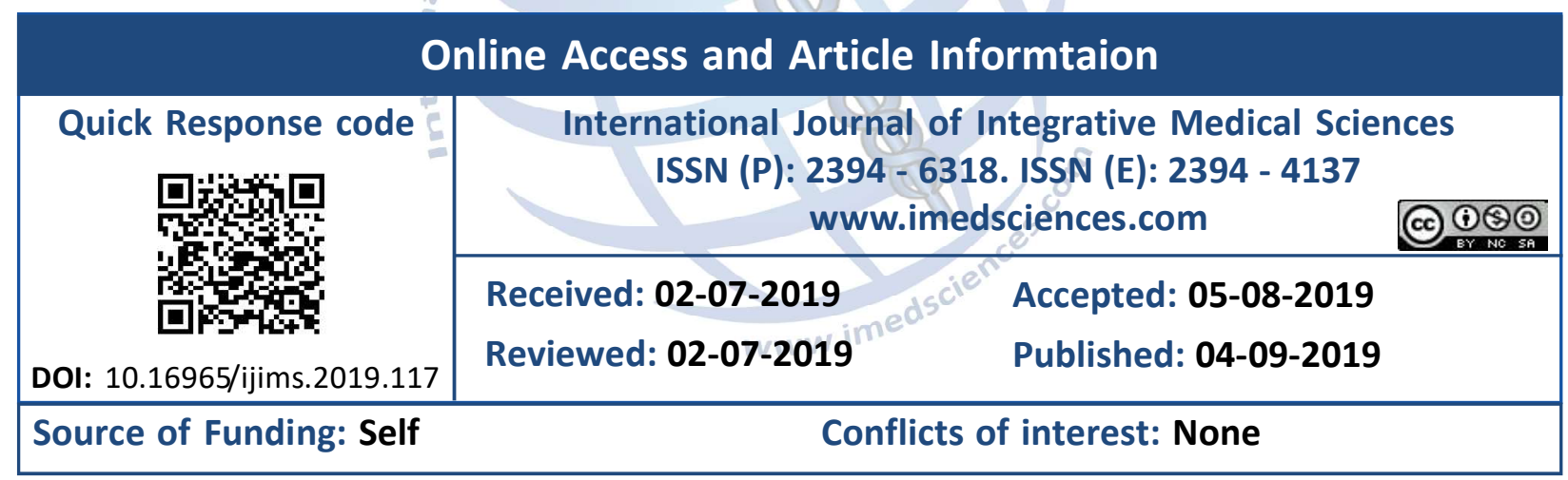

\section{INTRODUCTION}

Peripheral IV catheterization (PIC) is the most common invasive procedure performed on hospitalized patients. It requires manual dexterity, technical competence, knowledge of pharmaceutical therapy and familiarity with the anatomy and physiology of the vascular system. Visual infusion phlebitis (VIP) score tool for the assessment of the early signs of phlebitis along with prompt removal of peripheral intravenous cannula has been very successful in reducing below the acceptable rate of $5 \%$ [1]. Numerous factors can influence the development of phlebitis, such as inadequate technique when inserting the catheter, the patient's clinical situation, the characteristics of the vein, drug incompatibility, tonus and $\mathrm{pH}$ of the medicine or solution, ineffective filtration, catheter diameter, size, length and material of manufacture; prolonged use [2].

Phlebitis can be split into four types: mechanical: when movement of the cannula inside the vein causes friction and inflammation, or when the cannula is too wide for the vein; chemical phlebitis: caused by the drug or fluid infused through the catheter, where factors such as $\mathrm{pH}$ and osmolality can significantly impact the incidence of phlebitis; bacterial: when bacteria penetrates the vein, starting as an inflammatory response to catheter insertion and subsequent colonization of the site by bacteria. 
Bacterial phlebitis can create serious complications due to the potential for the development of systemic sepsis. Post-infusion phlebitis normally appears 48 to 96 hours after the catheter is removed. Incidence is related especially to catheter material and the length of time the catheter remained in the patient's vein.

Phlebitis manifests in four grades: Grade 1 erythema around the puncture site, with or without local pain; Grade 2 - pain at the puncture site with erythema and/or edema and hardening; Grade 3: pain at the puncture site with erythema, hardening and a palpable venous cord; Grade 4: pain at the puncture site with erythema, hardening and a palpable venous cord that is $>1 \mathrm{~cm}$, with purulent discharge [3].

Over a billion peripheral intravenous catheters (PIVCs) are inserted each year in hospitalized patients worldwide. However, international data on prevalence and management of these devices are lacking. The global audit involved 14 hospitals across 13 countries, with 479 patients screened for the presence of a PIVC. 59\% of patients had at least 1 PIVC in place, and $16 \%$ had other types of vascular devices. $25 \%$ of patients had no vascular device in place. The majority of PIVCs were inserted by nursing staff or a specialist team. The prevalence of idle PIVCs in place with no fluid or medication orders was $16 \%$ and $12 \%$ of PIVCs had at least 1 symptom of phlebitis [4].

\section{MATERIALS AND METHODS}

Peripheral Intravenous phlebitis rates as measured by visual assessment of the PIV site is dependent on the usage of a valid and reliable phlebitis scale. The visual phlebitis (VIP) scale, a modified version of the original Maddox scale, was developed to numerically rate phlebitis based on observable symptoms. This scale recommends a specific action for each numeric rating. Standardized use of this scale can eliminate dwell time as the predominant variable for changing peripheral PIV sites.

\section{RESULTS}

Fig. 1: Adherence to audit Criteria's.

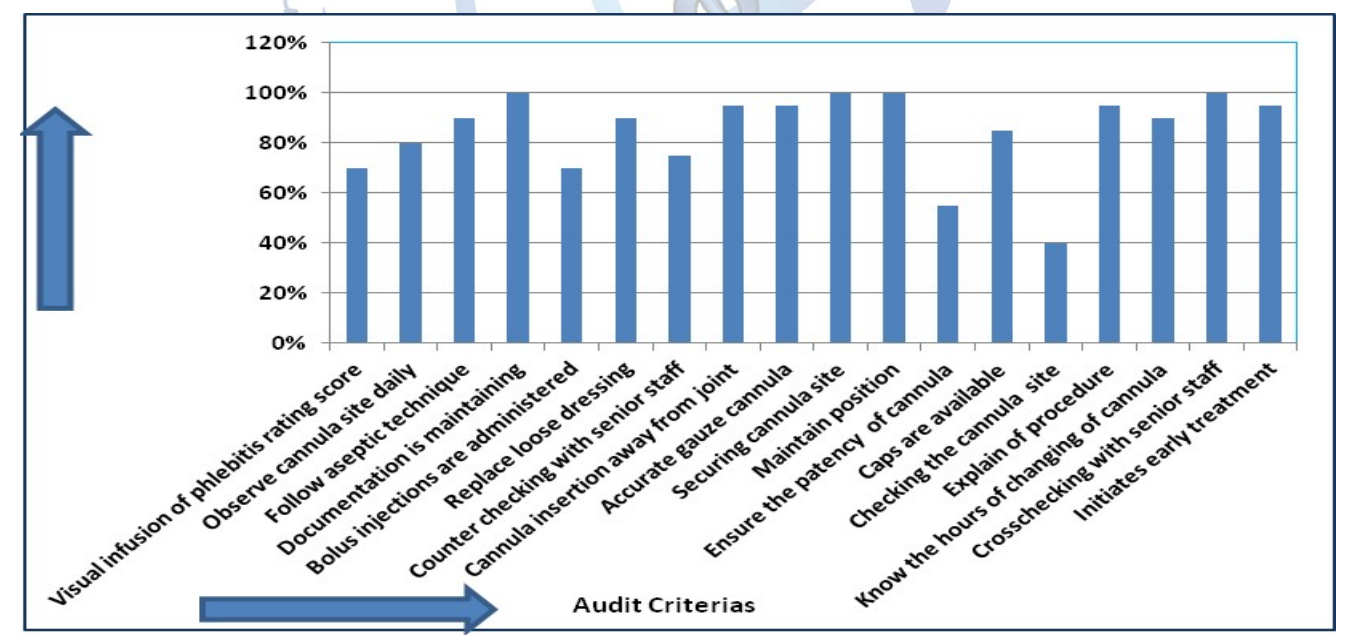

\begin{tabular}{|l|l|}
\hline \multicolumn{1}{|c|}{ IDENTIFICATION OFTHE PROBLEM } & \multicolumn{1}{c|}{ ACTION PLAN } \\
\hline $\begin{array}{l}\text { 1. The site of the Cannula is not observed daily. } \\
\text { 2. Some of the ward doesn't have Visual Infusion } \\
\text { Phlebitis Rating score }\end{array}$ & $\begin{array}{l}\text { To encourage to obs erve cannula site daily. } \\
\text { Rating Score. }\end{array}$ \\
$\begin{array}{l}\text { 3. } \quad \text { Bolus Injection is not administered. } \\
\begin{array}{l}\text { 4. Ensuring the patency by flushing the cannula } \\
\text { with 0.9\% NaCl daily or with Heparin Flush is not } \\
\text { done. }\end{array}\end{array}$ & $\begin{array}{l}\text { To suggest to flush the cannula with } 0.9 \% \text { NaCl or Heparin flush for } \\
\text { maintaining patency. }\end{array}$ \\
$\begin{array}{l}\text { 5. Checking the cannula site for risk of phlebitis } \\
\text { with the visual phlebitis scoring is not done. }\end{array}$ & $\begin{array}{l}\text { To encourage to check the cannula site with Visual Phlebitis Score } \\
\text { for the risk of Phlebitis. }\end{array}$ \\
\hline
\end{tabular}


Keeping this in view nursing audit had been conducted at down town hospital, Guwahati.

Audit statement: Identification of phlebitis for patients with IV cannula/infusion through visual phlebitis scale/score.

Audit objectives: To assess the nurses knowledge regarding the visual infusion phlebitis rating score.

Plan of Action: Based on the audit statement and objectives, the SOP has been made and it has been circulated to the various ICU's and wards prior to the audit so that the nurses are aware of the standards statement. 18 audit criteria has been established and after taken prior permission from the Executive Director, down town hospital, Guwahati, the audit has been conducted.

\section{CONCLUSION}

Hospital is a busy environment, nursing staff need to be aware that the systems they work in are in need of constant refinement to optimize working conditions and minimize the potential for harm. The introduction of VIP score at various ICU and wards has clearly had a significantly beneficial effect. Training sessions on implementation and use of VIP score by the staff nurses and senior nurses in the hospital is really going to benefit the patients in prevention and control of infusion related phlebitis.

\section{ACKNOWLEDGEMENT}

$4^{\text {th }}$ Year BSc Nursing Students (Session 2017-18) of SankarMadhab College of Nursing, Assam down town University, Guwahati.

\section{REFERENCES}

[1]. Tzolos,E, Salawu A. Improving the frequency of visual infusion phlebitis (VIP) scoring on an oncology ward BMJ Quality Improvements Reports 2014u205455.w2364 doi: 10.1136/bmjquality. u205455.w2364.

[2]. Alexandrou, Evan, Ray-Barrue, I G et al. International Prevalence of the Use of Peripheral Intravenous Catheters. Journal of Hospital Medicine. 2015;10(8):530-33.

[3]. Urbanetto, J, Cibelle G P and Tássia A M. Incidence of phlebitis associated with the use of peripheral IV catheter and following catheter removal Published online 2016 Aug 8. doi: 10.1590/15188345.0604.2746.

[4]. Boyd, S. Aggarwal, I et al Peripheral intravenous catheters: the road to quality improvement and safer patient care. Journal of Hospital Infection 2011;77(1):37-41.

[5]. Gallant, P. Alyce, A.Schultlz Evaluation of a visual infusion phlebitis scale for determining appropriate discontinuation of peripheral intravenous catheters. Journal of Infusion Nurse 2006;29(6):338-45.

[6]. Singh, R., Bhandary, S., \& Pun, KD. Peripheral intravenous catheter related phlebitis and its contributing factors among adult population at KU Teaching Hospital. Kathmandu University Medical Journal 2008;6(4):443-447.

How to cite this article: Manashi Sengupta. USE OF VISUAL INFUSION PHLEBITIS (VIP) SCORE TO CARE AND CONTROL INTRAVENOUS (IV) INFUSION RELATED PHLEBITIS. Int J Intg Med Sci 2019;6(5):836-838. DOI: $10.16965 /$ ijims.2019.117 